\title{
Power in society, economy, and mentality: Towards a semiotic theory of power*
}

MARTIN SIEFKES

\begin{abstract}
It is a well-known fact that power is closely connected with signs, but usually this connection is thought to be "after the fact": signs representing a power whose origin could be understood in non-semiotic terms. In this paper, a different view is introduced: power is an inherently semiotic phenomenon, which can be analyzed with concepts of cultural semiotics. To reach this aim, the three areas of culture defined in Roland Posner's theory of cultural semiotics are taken as basis for definitions of three types of power: power of position, power of disposition, and power of interpretation. These main types of power are delimitated from each other, further differentiated and carefully examined in their semiotic as well as sociological dimensions. The conclusion is reached that the full range of power phenomena can be analyzed with the help of cultural semiotics.
\end{abstract}

Keywords: power; authority; institutions; property; interpretation; cultural semiotics.

\section{Introduction}

Power has to do with signs; this is nothing new. In fact, in thinking about power we can be struck by the two-fold shape in which we encounter it: On the one hand it manifests itself as quite corporeal (all too real for the victims) when it is enforced as violence - e.g., a death sentence is carried out. At the same time, it demonstrates its subtlety as a sign relation when, for example, this same death sentence becomes valid through the application of a stamp or is stayed when the stamp is missing. Thus throughout history individual documents have deployed power that affected the lives of hundreds of thousands; well-known examples are the Edict of Nantes ${ }^{1}$ or the Edict of Fontainebleau. ${ }^{2}$ This duality in its appearance has been 
repeatedly understood as a paradox, because it has seemed nearly impossible to describe these two forms of power as a single phenomenon, to think together what we might call the "ethereal sign-nature" and the "corporeal force-nature" of power.

Semiotics can help us here. Though it is often just called the "study of signs," semiotics is the study of sign processes and sign users as well. It is in this broader sense that it gains the ability to describe the society, economy, and spiritual state (mentality) of a particular culture; these tasks are taken up by cultural semiotics. Semiotics thus is the first science that offers the necessary concepts and descriptive models for explaining power both in its aspect as sign process and in its aspect as social phenomenon shaping human relations, thereby illuminating the two-fold nature in which power manifests itself.

A further characteristic of power that has frequently prevented an indepth analysis is its apparent polymorphism as a social phenomenon. Let's examine three examples that are usually considered to be power:

1. (a) A state president or (b) a well-known personality makes a statement which, regardless of its argumentative quality, is covered extensively in all media, and which will therefore, if it is not entirely implausible, influence many people. A different person contradicts the statement in detail and on a high argumentative level, but their argument is only brought to the attention of a fragment of the influenced people, if at all.

2. A billionaire decides to build herself a luxury estate. She buys a large piece of property with a number of neighbors who are influenced by her activities, uses a lot of artifacts (building products and furniture) and determines the lives of many people for a certain time - namely, all those who are directly or indirectly involved in the construction.

3. The manager of a business, by signing his name onto a document, sets the firing of 10,000 employees into motion. For many of these people this means that they must look for a new employer as well as change the circumstances of their lives (due to a new job, a possible relocation, a different salary, etc.). For some of those affected, the manager's decision means unemployment and a decline in their social position. Even the decision to employ someone is an exercising of power. ${ }^{3}$

These three examples show how different the ways in which power works are. At first glance, there is hardly any similarity between these three persons - except, for course, that we would ascribe power to them! Let's compare the three cases more closely: The persons in examples (1) and (3) are well-known, and there might even be a protest against their ac- 
tions; in example (2) both would be atypical. In the case of (1a), those that feel affected by the statement can try to resist the power by electing a different president, ${ }^{4}$ in case (3) this is not possible. In (1a) and (1b) as well as in (3) an argumentation that throws doubt on the statement or decision may, under certain circumstances, be helpful, while in (2) the decisionmaker is not assumed to have to defend her decision; on the other hand, she uses up a part of her power (if she's not careful, it might not be enough to finish the project), while in the other cases power stands to grow through its use. In the case of (1b) there are once again special rules; depending on the effect of the statement, power can be increased or decreased through its use. ${ }^{5}$

How can we place all these different examples under the same concept of power? The differences described - and the list could go on - seem to indicate that "power" can only be described generally, while more precise examinations of its meanings and characteristics produce an irreducible proliferation. Cultural semiotics, however, provides a way out of this apparent dead end: It allows us, on the one hand, to decipher more precisely the phenomenon of power; on the other hand, it will help us understand the differences in the given examples. We will see that these are not incidental, but indeed indicative of three basic types of power (see Sections 4.1 to 4.3 ). These can be linked with the three areas of culture which are differentiated in cultural semiotics (see Section 3). We can thereby precisely distinguish the varieties of power from one another (see Section 5) and explain their differences as well as their mutual dependencies.

\section{Power}

\subsection{Towards a definition}

A definition of power that has meanwhile become a classic is given by Max Weber in Wirtschaft und Gesellschaft (Economy and Society). For Weber, power is "every opportunity, within a social relation, to assert one's own will even against resistance, regardless of what this opportunity is based on" (Weber 1956 [1922]: 1.28). Even more concise is the definition in the second volume of the same work as the "opportunity to force the behavior of others to one's own will" (Weber 1956 [1922]: 2.542). ${ }^{6}$ This definition covers the desired area precisely enough and will be used here as the foundation of our definition.

It should be noted that many phenomena of power are discussed by Weber under Herrschaft ("rule"), which he understands as a special case of power and defines as "the opportunity that a particular command with a 
specific content will be obeyed by a certain group of persons" (Weber 1956 [1922]: 1.28). The advantage of the concept for Weber is that it sums up precisely the means and manner of implementation (through "command" and "obedience"), while the concept of "power" is "amorphous"; he then proceeds on the basis of this concept of rule to analyze the historical forms of statehood up to democracy (Weber 1956 [1922]: 2.5412.876). This seems to make little sense, since, used in this way, "rule" approximates to "state power," which is by no means exercised through commands only. ${ }^{7}$ Indeed, Weber ignores the role of economic power in his discussion of state power, though he addresses it extensively in another context (Weber 1956 [1922]: vol. 1 ch. 2). It therefore seems better not to take up Weber's differentiation between "power" and "rule."

Allen H. Henderson discusses the lack of accord between different sociologists on whether "actual power" or "potential power" should be used as the basic model for power of position (Henderson 1981: 9-10). Here, though, this distinction itself is problematic. This is because power is always based on a possibility: If a bank robber threatens a teller with a pistol, does he only have power over the teller if he then demands money? Or, even, only if he actually receives money? Both seem implausible. The mere fact that he has a pistol and is holding it to the teller's head creates a power situation. This can be seen, for example, in that the teller could begin to open the register even before an explicit demand was made to do so; despite this, no court would find him guilty of disloyalty.

"Potential power" only makes sense as a concept if it is used to refer to a power potential contained in a situation, which can either be realized, or not by the participants. "Potential power" exists, for example, if an employer, due to his shy behavior or for other reasons, does not actualize the power which he could have over his employees: He could fire his rebellious employees, demoralize them with unpleasant tasks, or — if both of the above are prevented by legalities or corporate structure - at least deprive them of support, but his workers know that he won't do so because of his personality. The structural asymmetry of the situation, which allows us to speak of power (cf. 2.2) is present; at the same time, there's no "actual power": The employees can allow themselves to behave, at least to a certain degree, as if their employer couldn't get back at them.

If, on the other hand, I wanted to define "potential power" simply as power not directly and visibly used, I would no longer be able to adequately describe power relations that always consist of the potentiality of an (punishing, rewarding, admonitory) event that might well be never realized. I would then have to say that someone has more power when he uses his means of power (cf. 4.3.1) more extensively (let's say, by giving more commands as an employer; by calling in the army as a president); whereas 
I would in this case prefer to say that he has only used his power more decisively.

These problems can be solved by defining the concept of "power" as the opportunity to do something, namely to assert one's will, as in the definitions of Weber. As opposed to potential power, this formulation clearly shows that the existence of power is always defined through the possibility of its use, so that it is very real power even when not being exercised. If "power" is thus defined, we obtain for "potential power" the usage we have found to make sense, describing the potentiality of a power relation that might or might not be actualized.

\subsection{Definition}

Power does not have to be based on explicit means of exercising it; it can also be produced by an asymmetry of the situation.

On the other hand, not every asymmetry represents a case of power: The opportunities awarded by personal talents, capabilities or by competence cannot be included in a description of power sensibly. This should be clear from the fact that it is one of the hallmarks of the presence of power that it can be used to force the will of the power-holder independently of his competence; whereas the influence of competence might lead to a person convincing others to do as she thinks best.

It therefore makes sense to say of this asymmetry that it is based on conditions of social or institutional organization. Such an asymmetry shall be called a structural asymmetry.

Def: "Power" is defined as the sum of opportunities of a person to impose his/her will on one or more people due to a structural asymmetry in a given situation.

Two further examples should make this distinction clear:

- If a chronically ill patient requires a particular medication for his wellbeing that is produced only by a particular company, a structurally asymmetrical situation arises and a power relation develops.

- On the other hand, it is not a question of power in the sense of my definition if a pianist is able to draw all attention to herself while the concerts of her colleagues remain empty - provided that this situation is the result of the will of the concertgoers. To the extent that there is no structural asymmetry in the situation (such as one-sided media coverage or advertising), the concertgoers can freely decide between the various possibilities; it is therefore the case that the differing levels of 
success can be ascribed to natural authority (see Section 4.1.2) and not to power. The decisive factor here is that the situation itself is structurally symmetric: In the example above, all pianists have had good training, they have all been written about, and they all have the opportunity to perform. If the pianist above is given more support because, for example, she has placed herself under the tutelage of an important mentor, a structural asymmetry is produced: The fact that everyone is talking about her is now related to the fact that the situation was influenced by her having more prestigious performance opportunities, a larger media response, or a more famous orchestra as accompaniment. The pianist herself does not have power at this point (though she could acquire it quickly if she becomes famous); her success is nonetheless a result of power.

The somewhat cumbersome term "structural asymmetry" is chosen here in order to designate a particular kind of asymmetry. An asymmetry is also present if the pianist is simply so much better that no one wants to hear her colleagues; this asymmetry, however, is introduced by the pianist herself. "Structural asymmetry" therefore is meant here to designate a situation that is, independently of behavior and of the abilities of the persons involved, already asymmetrical.

By the structure of a situation I mean all facts that are not persondependent, but can have an influence on the situation. Used in this sense, the structure of a chess game encompasses the pieces, the board, the rules, and the conventional varieties of the game. Additionally, the structure of the situation in a particular game of chess encompasses factors such as background noises and lighting. It is important to note that the structure of a situation can, naturally, be influenced by earlier behavior of the persons involved; a situationally specific analysis is therefore necessary.

If one accepts the definition of power given above, power is present, for example, in the case of a game if it has unequal rules, or when other facts generate a structural asymmetry in the situation, for example, when the wind is favorable to one player in a game of tennis. Compare this with another purely imaginary game: The astounding asymmetry that would emerge if I was to play against a Wimbledon champion would, unfortunately, have little to do with power ...

\section{Three aspects of culture}

For an adequate semiotic description of power, a cultural semiotic approach that can describe society and culture as phenomena constituted by 
sign processes is necessary. The cultural semiotic approach of Roland Posner shall serve as a basis here (Posner 2004). This approach makes a triple division of culture by differentiating between "social culture" (the range of sign users and institutions of a society), "material culture" (the range of artifacts of a culture), and the "mental culture" (the range of mentifacts of a culture). On the basis of this triple division the concept of power can be explicated. For that reason, we should look into it in more detail.

\subsection{Social culture}

The social culture of a society is considered to be its structuring into individual sign users and their interaction, as well as groups of sign users and their interaction. Groups of individuals who are connected on a regular basis by sign processes and who can in their totality function as a single sign user towards the outside world are called institutions (Posner 2004: 66).

For a long time, social culture was seen as the only, or at least most important, site of power and power relations. We will see, though, that this assumption falls short.

\subsection{Material culture}

The material culture of a society is considered to be the totality of its artifacts as well as the knowledge of their production and use (Posner 2004: 67). The theory defines as an artifact everything that is the product of intentional behavior, regardless of whether the result itself was intentional. If an artifact not only has a function, but is also a sign that carries a coded message, it is called a text of that culture (Posner 2004: 68). This includes impermanent signs such as musical or theatre performances.

\subsection{Mental culture}

The mental culture of a society consists of its mentifacts. Mentifacts are ideas and ways of thinking, concepts and interpretations present in a society (Posner 2004: 70). Semiotically, these are codes and conventional signs. ${ }^{8}$ Examples of mentifacts are the following:

- Languages and dialects

- Scientific theories 
- Conventionalized usage of elements with a given meaning in the arts ("aesthetic codes")

- Terms and concepts

- Religious beliefs

- Moral values

All codes that a society uses are mentifacts. Of importance is the distinction between primary codes (a language; a system of traffic signs; musical notation, etc.) and the secondary codes based on them (literary genres as well as styles of code usage in the arts and in everyday life; musical styles and performance practices, etc.). Every use of a code is a text.

Three examples should clarify the division between mentifact and artifact (with the special case of text): A book is not a mentifact, but a text of a culture. Equally, an image or the facade of a house are also texts in this sense, because they all have coded meanings, and every artifact with a coded meaning in a particular culture is a text of that culture. All three are based on mentifacts, which is to say, on codes:

- A book is based on language, arguably the most important code of every contemporary culture, as well as on further, secondary codes, which I will call aesthetic codes, such as the code of literary genres and traditions to which it must always relate in one way or another (if only in repudiation); the code of literary language use ("style") which it uses or (in some cases) expands; etc.

- An image is based on similar aesthetic codes. The role of language (i.e., the establishment of a primary codes on the basis of which experiments can be carried out) is here assigned to the code of representation (e.g., central perspective), various technical codes (e.g., painting in oil, fresco) and the knowledge of their utilization, colors and their partly conventionalized use, etc.

- A facade is also based on a primary code: Here it is the repertoire of shapes such as windows, doors, gables, ledges, balconies, roofs, etc. Secondary codes based on the primary code, which can be more or less conventionalized, include architectural styles (e.g., Classical, Modern) and individual styles of single architects.

\section{Three types of power}

From a semiotic perspective, the general phenomenon of culture can be divided into the aspects of social culture, material culture, and mental culture. In all three areas specific phenomena of power can be found. The chosen cultural semiotic approach allows us to describe these diverse phe- 
nomena of power on the basis of a semiotic description of the three areas of culture. The advantage of this method — giving a semiotic description of power on the basis of a semiotic approach to culture - lies in the fact that now phenomena of power can be described systematically, building up from a few clear-cut concepts, whereas at first sight they seemed too diverse for an in-depth analysis (see the examples in the introduction).

These three examples, in fact, were not randomly selected: It will become clear that they correspond to different semiotic types of power, each of which is located in a different semiotic area of culture. Also, the differences noted between the examples are not random. Rather, they reveal that the three types of power have different characteristics. The strength of the cultural semiotic description of power reveals itself in its ability to give a clear-cut bottom-up analysis of these differences, which are empirically verifiable (see discussion in the introduction), requiring for this task only a few equally clear-cut basic concepts of cultural semiotics and the said three-area division of culture. In what follows, the three types of power will be detailed individually; the order of the cultural areas which form their basis will for reasons of presentation be reversed. In Section 4.1, power of interpretation will be dealt with, which is located in the area of mental culture (see Section 3.3); in Section 4.2 power of disposition will be dealt with, which is located in the area of material culture (see Section 3.2 ); and in Section 4.3 power of position will be dealt with, which is located in the area of social culture (see Section 3.1).

\subsection{Power of interpretation}

\subsubsection{Definition}

Def: "Power of interpretation" is defined as the sum of opportunities of a sign user of a particular culture to define and/or distribute mentifacts as a part of that culture's mentality.

Power of interpretation is located in the area of mental culture.

The qualification "as a part of that culture's mentality" is of importance. The capacity to define new codes depends to a great extent on education, intelligence, and talent of the individual; in itself, it is not yet a variety of power. It is, however, a prerequisite for the development of power of interpretation. Its creation depends on various factors that enable the distribution of new codes. These include the following:

- Media access (the opportunity to use a particular medium, as a sender)

- Media presence (the extent to which one has media access) 
- Media competence (the degree to which someone knows how to use a medium for his/her purposes)

- Expert response (the reaction of the experts or critics, as they are called in the arts)

- The size of the circle of acquaintances who can be "directly" influenced. ${ }^{9}$

What are mentifacts? According to Posner these include the following:

- All the codes of a society

- Its ideas

- Its general concepts (for example "human" and "animal," "heaven" and "hell")

- Its values (for example "freedom" and "equality" or, more up-to-date: "personal responsibility")

Such mentifacts can be understood as codes, first, because there must be something that expresses them (a "symbolic form" in the sense of Ernst Cassirer), which is to say, a signifier; and second, because the connection of this signifier to a signified is of a conventional nature (Posner 2004: 70): The arrangement of meaning could be different. ${ }^{10}$ They thereby fulfill the requirements for codes.

A central problem for the understanding of this type of power is the differentiation between power of interpretation and natural authority.

\subsubsection{Natural authority versus power of interpretation}

Def: "Natural authority" is defined as the sum of opportunities of a person, based on past actions and achievements in a particular area, to find for the texts and/or mentifacts they produce in others on the one hand an interest, i.e., the willingness to receive them, on the other hand acceptance, i.e., the willingness to be prejudiced in their favor.

The natural authority of a famous writer thus consists of the fact that many people want to buy his new book, and the natural authority of a physicist of the fact that her new theory is, regardless of its first impression, carefully examined by the scientific community.

Natural authority is closely related to the concept of "reputation," which designates the opinion all the people who know (about) a person have of this person, insofar as it is based on certain achievements, abilities or character traits of this person. Thus, "reputation" means just that part of the general opinion that is based on personal life and work, and excludes social standing (which is not to say, of course, that it is always fair!). It is 
part of the reputation of someone if it is generally assumed that "he plays very well," but not that "he is very well connected" or "she is a professor." It should be noted that "reputation," in this sense, can only usefully be employed in speaking of groups of people who are reasonably wellinformed about other people's achievements, as in scientific communities, work groups, close-knit communities etc. On this basis, "natural authority" can be said to be the direct influence people have on other people based solely on their reputation.

It is important to note that natural authority is not a moral category and has nothing to do with "real value," whatever that may be. Artists, intellectuals or "stars" of every description do not gain natural authority because they are "good" in any objective sense, but only because the audience likes them. A writer like Joyce didn't get much recognition from most readers of his time even though he is now considered to be one of the most innovative and brilliant authors; he never had great natural authority in his lifetime, though he gained some through critical recognition. In addition, it should be pointed out that natural authority often accords its holders power of interpretation, when, for example, a film star is asked for her opinion on politics where s/he has no record of achievement whatsoever.

The distinction between power of interpretation and natural authority is important for the following reasons:

1. Natural authority is sometimes taken to be a form of power and can in fact be hard to distinguish from it, for example in the case that a superficial utterance produces a large reaction, and is then discussed instead of more substantial utterances by other people. The difference to power, however, can be seen in the fact that it is precisely in the absence of power that natural authority comes into play, whereas in the presence of power, the distribution of resources (in our example, attention) is regulated by laws, conventions or by decisions of the powerful. As a cross-check, it can be shown that power is necessary to prevent the effect of natural authority: The attempt to create an equal reaction to every utterance, for example by producing an identical print run for every author or giving each published book exactly twenty lines in the Arts and Leisure section, would certainly be feasible only with a decisive use of power. The use of power is even clearer if natural authority is to be excluded in personal relations, as in very conservative societies where there are strict rules regarding the reverence people have to show other people depending on social position, and choices cannot be made according to the workings of natural authority. ${ }^{11}$ 
2. Natural authority and power of interpretation lead to outwardly similar results, for example stronger media presence.

3. Natural authority is self-regulating, while power of interpretation is not. If an author follows a strong book with a weak one, one can assume that it will receive more attention than it deserves (and vice versa); this will even itself out, however, with the following book.

By a person's authority I mean the probability of others doing what s/he wants, but with this doing based not on a structural asymmetry in the situation. The second part of the previous sentence distinguishes authority from power.

Natural authority should be carefully separated from artificial authority. As artificial authority I define any authority that is not natural in the sense of the above definition. For example, the authority of a teacher is partly artificial authority. Of course, teachers can, like any other person, develop natural authority on the basis of their capabilities, personality, or previous behavior. Usually, the authority a teacher can muster consists - apart from the power of position that results from the asymmetry in the teacherpupil situation (see 4.3.2) — of both kinds of authority, but they can be separated. Artificial authority can be removed by abolishing the social markers it rests on, for example titles, functions or prestigious posts. The authority that remains is natural authority. Thus, some people are "born teachers" and will gain respect in every teaching situation, formal or informal; an able scientist will have the reverence of colleagues even after losing his/her job.

As already mentioned, in normal teaching situations power of position, natural and artificial authority work together. But when the pupils meet their teacher after completing or changing school, the respect they show will be based only on authority since the teacher/pupil situation with its structural asymmetry has ended. If the same person lived in a community where social functions like "teacher" were unknown, her abilities and personality alone — natural authority — would define the respect she commanded in teaching.

Again, it is important to note that this is not a moral distinction; thus, natural authority in the sense of our definition includes the effects of character traits, personality, and even deception and dazzling on others, whereas other people are brilliant or morally good, but are not able to make an impression on their surroundings and win natural authority. At the same time, artificial authority is not to be discounted as invalid in principle. Regarding our example, many teachers do a good job with the help of artificial authority, whereas they would be helpless without it, having a personality that makes little impression on pupils. 
4.1.3. The production of mentifacts. The production of mentifacts takes place in various areas of society. In modern Western societies two areas are especially noteworthy: one is the universities; the other is the area which, in Germany, is traditionally designated as Kultur ["culture"] in a more narrow sense (for example when a newspaper has a Kultur section which includes art, literature, theatre, etc.), the area of artistic activity of individuals and institutions which in English typically is called "the arts."

Imagine a university that uses only available mentifacts (codes or conventional signs; see 3.3), failing to develop any new ones; it would probably be called "unscientific" and its status as a university might be disputed. For a high school, on the contrary, no development of mentifacts would be expected. In Germany, at college level traditionally the Fachhochschule was thought to provide a rapid, discipline-specific and efficient academic education, whereas the Universität in the tradition of Wilhelm von Humboldt was meant to combine a "universal," interdisciplinary education with a focus on research and creativity. Due to university reforms of the past years, however, a rapid convergence is taking place.

Codes are also created in the field designated Kultur in the more narrow sense. Here experimentation can and should take place as freely as possible from direct necessities. Though often a code or many codes are already available in a particular area, the cultural accomplishment is more highly valued the more innovative its code is. Schools of thought form around the question of whether one code or the other is preferable, and they battle each other in publicly interesting ways. But old codes have their followers as well; who see themselves as "conservative" and are of the opinion that innovation should not be taken too far.

But mentifacts are also created in other areas of society. Businesses develop new methods for solving technical problems and register these methods as patents; such methods, despite their practical character, are also mentifacts to the extent that they create new codes, new signs or new usages of them. In addition, businesses access the mentality of a society through the modern concept of trademark, i.e., the right to exclusive determination of certain signs by certain people. Other sign users are the addressees of these signs, but they are not allowed to use these signs (as senders) without permission of their owners in certain areas of society. Their use is especially prohibited in a negative context. The concept presupposes the possibility of separating the creation of a sign (the determination of the connection between signifier and signified) from its passive consumption, a separation that does not take place in natural language and other largely self-regulating codes.

Since, however, these business signs (trademarks) have become of fundamental importance for the culture of a capitalist society, artists 
especially find these restrictions to be a massive threat to "artistic freedom," which in their opinion has to include the free use of all signs relevant to a particular society. Other people feel that everyone who is the addressee of a sign should have the right to be its sender, too. ${ }^{12}$ Special forms of protest have therefore developed against trademark authority, for which there are even specific publications. ${ }^{13}$ Whatever one's opinion in this question, it cannot be denied that the idea that signs can be owned introduces power into a community of sign users, since it creates a structural asymmetry of the situation (see 2.2) by giving sign users different rights over the signs they communicate with.

Mass media and advertising are also becoming increasingly important as producers of mentifacts. It is important to note, though, that the contents produced by them, like those of the field of culture in the narrow sense, are primarily texts. Initially, media and advertising limited themselves for the most part to text production, but with growing competition they see themselves more and more as producers of mentifacts and are becoming a serious competition for traditional mentifact producers (universities and the arts, see above; and also churches, governments, and philosophy). They therefore develop new types of programs and campaigns, which are meant to function as new codes in society. Examples of successful mentifacts of this type include the "Big Brother" show, which changed the conceptualization of the private/public distinction and the limits of self-presentation in many countries, and the German advertising slogan Nicht immer - aber immer öfter! (not always, but ever more often), introduced by the brewery Radeberger to indicate the alluring qualities of their beer, which (due to its general applicability) for some time became a ubiquitous popular dictum. ${ }^{14}$

In many areas of daily life, new codes or new signs are generated inside existing codes; frequently, small, informal groups of sign users play a role in this. To the extent that these groups appear to the outside world as a unit, and between themselves use characteristic signs such as distinctive clothing or verbal expressions, they display the semiotic characteristics of institutions (see definition in 3.1). Though such groups rarely invent entirely new codes, they often contribute decisively to code change within specific areas of daily life. Their role is most notably in "life style"-areas such as clothing, leisure activities, sports practice, gestures, and daily speech and slang. Before such new codes disperse through an entire society (during which process they generally mingle with known codes), they are frequently used, in a weakened but still discernible version, by a larger group of people who sympathize with the "different" style of the original "in-group," without being able to live, speak, and think fully like them. In this stage, the larger group is often referred to as a subculture. 
4.1.4. Types of power of interpretation. The discussion up to this point may have produced the impression that mentifacts consist, apart from inventions, mostly of statements of opinion.

A clarification is therefore in order: In fact, statements in and of themselves don't belong at all to the category of mentifacts; they are texts and thus belong to the area of material culture. To draw the distinction precisely is not easy. What is certain, though, is that the interpretation of the world that shows itself in most statements of opinion lies in the sphere of mentifacts. An example may be illuminating: When someone is invited to give their opinion on a socially relevant question, the utterance itself, its diction, its imprint on an audio recording, or its notation in a book, all belong to the area of texts. The political, economic, or aesthetic interpretations expressed in the utterance, however, are mentifacts, since they are codes of a particular culture that assign particular signifieds (namely, the interpretations) to particular signifiers (namely, the phenomena, events or other topics spoken about).

Naturally, statements of opinion are only one of the possible ways to create mentifacts through textual production and to spread them with the aid of power of interpretation. This also occurs, for example, in the following cases:

- Someone creates a book which for certain reasons is very widely read, and thereby has a lasting influence on the development of a language, as Luther did with his translation of the Bible (1521/1534).

- Someone has a lasting influence on the daily behavior of people through a ubiquitous media presence or through his/her place in the canon of important texts, ${ }^{15}$ as intellectuals, spokespeople, philosophers, and television moderators do.

- Someone invents an artificial language (such as "Volapük") or a new code (such as Shea Zellweger's "Logic Alphabet") and attempts to spread it using his celebrity.

- Someone develops a scientific or social theory and attempts to disseminate it using her position (e.g., a professorship) or through financial means.

- Someone becomes successful in a particular style of art due to critical praise.

- A shaman invents a new myth or alters an old one and causes his people to accept it.

- Someone creates a religious vision and threatens or promises something to his followers in the name of supposedly God-given authority.

- Someone, due to a position or financial power, has access to a medium and recommends moral values. 


\subsection{Power of disposition}

\subsubsection{Definition}

Def: "Power of disposition" is defined as the sum of opportunities a member of a particular culture has to access the artifacts and texts of this culture. The extent of power of disposition someone has depends, on the one hand, on the range and intra-cultural importance of the artifacts and texts $\mathrm{s} /$ he has access to, on the other hand, on the degree to which s/he can influence their use.

Power of disposition is located in the area of material culture.

$A$ note on the role of texts: Texts should be regarded as a sub-category of artifacts (cf. Posner 2004: 68) and as such fall in the sphere of power of disposition, though within certain limitations. The rights to a text (intellectual property rights) belong in our sense not to the sphere of mentifacts, but instead to the sphere of artifacts, since texts are not themselves codes, but instead use existing codes. It should be noted, however, that a text can become a mentifact to a culture. For example, the pantheon became one of Europe's most influential architectural models and as such a mentifact of European culture. Equally, the Faust legend has for many centuries belonged to the realm of mental culture in German-speaking countries and as such has detached itself from individual texts. ${ }^{16}$

In capitalist societies, power of disposition is determined to a large extent by "property." If I own something, I have complete power of disposition over it. On the other hand, power of disposition applies even outside the sphere of property:

- "Thief" and "robber" are words for someone who gains power of disposition over certain artifacts of a culture in disregard of the specific laws valid in that culture.

- The director of a museum has, to a certain extent, power over theartifacts (more specifically, these will usually be texts) of her museum. The director's power of disposition is produced by her position (see Section 3.2), but is not complete power. ${ }^{17}$ She can decide which artifacts are displayed, which are bought, and, in the case of many pieces, that they be sold. However, she cannot ordinarily order their destruction.

4.2.2. Money and property. In the area of power of disposition, capitalist societies have developed the concept of "property," which 
provides for complete power of disposition over things (also, with certain restrictions, over animals). Money serves as a symbolic representation of property; it underwent a process of gradual abstraction from concrete property to the symbolic representation of property, beginning with precious metals, which were needed in every community and were therefore suitable as a means of exchange, through the representation of such precious metals by coins and bills which were guaranteed by the authorities to be interchangeable for "the real thing" at any time, to "currencies," which are no longer linked to precious metals and are freely tradable on the financial markets.

Today, money, the symbol for complete power of disposition, is increasingly electronically represented. Such a representation is only possible if its conventionality is absolutely ensured, since otherwise no-one would give up their actual physical property: Only in very stable capitalist societies, is the immaterial figure stored in a computer which designates a bank balance considered equal to the actual possession of objects, for example of real estate or precious metals. One of the basic concerns of economists is to ensure a high level of faith in economic stability, in the absence of which people are loath to part with their concrete property for an abstract representation, as witnessed by the psychological effects of major depressions.

Since the concept of complete power of disposition has become fundamental to capitalist societies, it became necessary to preserve the exercise of power of disposition independently of presence, direct intervention, or personal supervision. It therefore became one of the state's primary duties to safeguard the power of disposition of its citizens.

The most important task of money, in this process, is to enable the free exchange of power of disposition at any time. This exchange is seen as necessary condition for the functioning of society. A distinct field of knowledge (economics) is occupied with the processes that relate to the exchange of power of disposition. In capitalist societies a motivating function is assigned to power of disposition: The assumption is that the pursuit of power of disposition leads many people to undertake activities that are beneficial to society. Often, a self-regulating function is also thought to exist: It is assumed that those who are especially talented at acquiring power of disposition are also those who should exercise it in the interest of society. ${ }^{18}$

4.2.3. Signs for money and property. Money is an abstract symbolic concept for power of disposition. As previously explained, it can therefore be represented in very different ways, for example with coins, with paper 
money, or in the form of "electronic payment" as simply a number in a computer network.

Equally, there are many forms of representation for property. Land holdings and real estate are marked on the ground with boundary stones; additionally, they are registered in official documents, such as the "land books" in Germany. Unofficial representations of land holdings include fences, walls, and locks, which as a rule have a double function: On the one hand they prevent access in a direct way (non-semiotic function). On the other, they signify a border iconically by retracing it and thereby making it visible, while at the same time accentuating it by signalling a boundary: "No trespassing." The importance of the semiotic function is obvious in those cases where it is enough to mark the border as such, i.e., to make it recognizable with a sign, as witnessed by the existence of those small walls and hedges that in villages often mark off front lawns without presenting any serious barrier to anyone. These are not necessary against possible claims of neighboring landholders or the state, since a symbolic marking (border stones, registration in the land books) suffices for this purpose; instead, they are intended to visualize an abstract concept, namely, to signal to visitors and outsiders the property rights on that piece of land.

There are also many other forms of property that are symbolically represented: Financial interests in a business are represented by shares, loans given to the state or to a business by government bonds and corporate bonds. In the latter case we are dealing with the transfer of power of disposition, which is already represented symbolically by money, to an institution (in our example, the state or a business). Initially, this creates only a right to the return of the (proportionally increased) symbolically represented power of disposition (i.e., money). Only if this does not occur can a direct power of disposition over the institution, or over parts of it, be made effective. The latter option, though, does not exist today in the case of national bonds, since no private person can have power of disposition over an entire state. In that case, in the event of non-payment, only limited rights against a state can be asserted, and even these (as the recent example of Argentina bonds has shown to investors) are fraught with difficulties in practice.

4.2.4. Types of power of disposition. Power of disposition appears in various forms. Let's start with a recapitulation of the two most important varieties:

- Complete power of disposition is usually designated "property." In capitalist societies this is the most important category, to the extent 
that no area of the central culture ${ }^{19}$ can be organized without it. In the peripheral culture, on the other hand, there are occasionally attempts to do without the organization through property. When these attempts are perceived as a threat by the most important holders of power of disposition, they usually attempt to box them off into the area of counterculture, as was successfully done in 1950 s America. ${ }^{20}$ Since then, most experiments aiming to reduce the importance of property have been denounced as "communist" counterculture, regardless of their organizational form being communist or otherwise.

- Authority derived from a position grants limited power of disposition. Thus the manager of a business has a degree of power over the property of that business as well as over the products produced by its employees; should he overstep the bounds of this power, he is considered to have committed embezzlement.

However, power of disposition also appears in additional forms:

- In the public sphere there are usually limiting rules regarding power of disposition, designed to prevent the destruction of what is termed "public property." A comparable set of limits holds for the extracultural sphere of nature and the environment, a sphere, however, where our cultural semiotic definition of power is inapplicable in the first place.

- Power of disposition is found in the private sphere as well. Thus married couples automatically share power of disposition over property acquired during the marriage unless explicitly stated otherwise in a "marriage contract." And power of disposition over the fetus is in many Western societies given to the mother only until a certain point in its development; after this point she loses power of disposition over her developing child and in the event of an abortion faces criminal charges.

- And finally, power of disposition can also be appropriated by violence, as states do in wars and private individuals through robbery. Weapons grant complete power of disposition because they can realize its worst form, the killing of living beings, thereby enabling their holders to force all other forms of power of disposition, such as determination over possession and behavior of individuals, by threat.

\subsection{Power of position}

4.3.1. Definition. The area of social culture (society) consists, from a semiotic point of view, of a range of sign users. In order to be able to analyze power relations, we must examine the structures that govern this 
sign usage; these are the institutions. We have already defined an institution in Section 3.1 as a group of individuals who are in contact with one another through regular sign processes and who can interact with the outside world as a single sign user (Posner 2004: 66).

How is the connection between institutions and power to be understood? Hermann Heller has developed a concept of institutions to deal with this question, although he speaks of "organizations" and not of "institutions" (Heller 1934: 231-233). Lutz Berthold characterizes it as follows: "The essence of the organization lies [for Heller] in a circular conditional relationship, wherein the power of the organs affects the power of the members and the power of the members affects the power of the organs; the outcome is an increase of the organization's power, the power of the whole" (Berthold 1997: 357). ${ }^{21}$

The circularity of the power processes in institutions explains how institutions can accord power to their individual members while at the same time themselves gaining power as independent sign users. But how does power come to be inside an institution in the first place?

Here we are helped by John Thompson, who for his concept of institution takes up the Bourdieuian concept of "field of interaction": A field of interaction, for Thompson, is a range of circumstances given in a particular situation and within which individuals follow their goals (Thompson 1995: 12). Individual people find themselves in various positions within these fields. Institutions are thus areas of society where a field of interaction remains stable for some time independently of individual people: "Institutions give a definite shape to pre-existing fields of interaction and, at the same time, they create new positions within these fields, as well as new sets of life trajectories for the individuals who occupy them" (Thompson 1995: 13). ${ }^{22}$

The power of a person is thus a product of their position within such a field of interaction. We are now in a position to form the following definition:

Def: "Individual power of position" is defined as the sum of opportunities a member of a specific institution has to attain his/her goals within that institution. "Institutional power of position" is defined as the sum of opportunities an institution has to attain its goals in a society.

Power of position is located in the area of social culture.

But how does a position give its holder influence on society as a whole? According to Thompson, people, through their positions in institutions, gain access to "resources" which they can use in pursuing their goals; we might call them means of power. Such means of power are on the one 
hand the structures, ordinances, and rules within an institution. On the other hand, there are means of power which impact society, for example media presence, the recognition I receive from a particular position in a particular organization, etc. In short, power of position also accords power of interpretation and power of disposition to its holder.

4.3.2. Institutions: Inside and outside. We have extended the concept of institution to include every group of sign users who regularly interact with one another using sign processes and who can interact with the outside world as a single sign user. Therefore, not only a family, a church or office but also a gang, a subculture or a circle of artists (such as the Brücke group) can be considered institutions.

Every person is a member of different institutions. In every institution $\mathrm{s} /$ he has a position, which is connected to specific power of position. We can distinguish two components of individual power of position; the first component regards the influence a member has on the institution itself. Those who can determine the destiny of the institution possess the highest power of this kind. In most organizations certain options are excluded; thus, the director of a governmental office cannot decide to shut that office, and even the Pope himself cannot dissolve the Catholic Church. ${ }^{23}$ Both, however, can decisively influence the development of the institution..$^{24}$

The second, equally important component of individual power of position is that which is exercised over other members of the institution. As far as power over individual persons is concerned, this component is often greater for those who are not at the very top of an institution, but rather further down or even directly above the powerless members of the institution. Thus, a works supervisor often has, in practice if not in theory, much greater power over individual workers than any CEO, be it only through his constant opportunities to learn their weaknesses, to help or bully them. A CEO, on the other hand, often has less power over his direct subordinates than these, in turn, have over their direct subordinates; at the same time, he has power over more people than any other person in the corporation. One of the advantages of rising in an institution consists of the fact that while one is still subordinate to higher-ranking people, one is less completely so; one gains more "elbow-room." 25

This second component of individual power of position, however, is distinct from that power which an institution as a whole has over its members. This last kind of power is often based on membership itself and is, curious as it may sound, not exercised by anyone as power of position. If, for example, the Catholic Church denies its members a church wedding 
after a divorce or if, in Germany, the traffic authority in Flensburg revokes a driver's license after repeated traffic violations, they do according to rules, codes, and statutes. Considerable power of position is produced, however, when individual people can decide on exceptions to such rules.

But for most members of institutions, that part of intra-institutional power that is exercised as power of position is much more tangible than the abstract power considered above. In a business, for example, the head of a department has, practically speaking, power over a particular part of his employees' lifetimes. He can decide what a small or large group of people do in that time. Since human beings are limited in their resources, the portion of energy, powers, capacities, and ideas of his employers that he can command is often greater than the share of their time he controls. In this manner, it is possible for him (within the limits set by predefined goals of the institution as well as by the power of position of his superiors) to realize his ideas regarding the institution.

A teacher is an example of a member who inside his institution (the school) has little individual power of position of the first kind. He cannot determine the fate of the school, and cannot even give input to the curriculum that he has to follow. On the other hand, he has power of the second kind: power over certain other members of the institution, namely, his students. The average teacher will teach several thousand students over the course of his career. While doing so he can influence their spiritual and moral development (and often has a significant role in it, which can be measured by the fact that many people indicate that teachers stimulated their interests, helped to shape their outlook on life and influenced their career choices). Most importantly, he can evaluate them with grades, which are important for the students' future career options and success in life. Naturally, this power is far removed from complete power, since grades cannot be given arbitrarily and are given by different teachers in different subjects.

Power of position should not be confused with similar concepts utilized by institutions themselves, which often serve to strengthen cohesion in the institution and to disguise the differences in power of position. A person with a position granting little power but which is important for the function of the institution is often spoken of as holding a "responsible position." "Responsible" means that an error on the part of such individuals can have significant results, meaning that they can easily go wrong while standing to gain little from doing everything right. Thus, the janitor of a business or school, the sexton of a community, the secretaries of a governmental office are responsible for the smooth operation of their organizations. As opposed to those in "leading" positions, however, they are not asked to make decisions. Sentences such as "I'll leave that to your discre- 
tion!" are characteristically addressed to people in such "responsible" positions; they mean that the responsibility is being passed down regarding how a particular task is to be completed, or how a particular problem is to be solved in light of the given necessities or directives. At the same time, they are supposed to suggest a transfer (even if limited and temporary) of power of position. They sometimes have the result that people are energetically engaged in tasks that they did not themselves choose and which they might otherwise not have cared about.

Institutions differ greatly in the amount of power of position they accord. In the past few decades there have been repeated attempts to find organizational forms that are less or not at all hierarchical. A key word here is flat hierarchy. Though this, as a rule, only means that there should be fewer levels of hierarchy, which can in turn also lead to a greater dependency of the lower-ranked persons on those in power.

It has become clear that every institution develops informal hierarchies, even if it is a clique of friends, a music group, an alternative housing project, or any other institution nominally based on equality between all members. Where hierarchies are not pre-set, they frequently develop on their own, and projects focusing on parity have often realized that they must develop specific behavioral guidelines that prevent the formation of power structures.

4.3.3. Rights. Being a part of an institution is often connected with certain rights that are independent of position. An example: If a member of a Christian church decides to marry in church or have their children baptized, the priest or pastor cannot arbitrarily decide to refuse. In many institutions, membership is connected with such rights. Rights, however, must be differentiated from power, for the following reasons:

1. Power always has an asymmetrical component (cf. definition in 2.2). If everyone is allowed to do a particular thing, we normally don't speak of power but rather of a right, even if this right is dependent on imposing upon another person. If I can demand something of you that you can also demand of me at any time, there is no power relation.

The same is true if everyone is able to do a particular thing. For example, during the Cold War the two "superpowers," the USA and the USSR, had power over the rest of the world (which justifies the designation as superpowers) but not over one another. Power is the sum of opportunities someone has for imposing his/her will on someone else, something which the adversaries didn't have as regards each other. Usually, the expression "balance of power" is used for 
characterizing the relationship between the two opponents; in the sense of our definition, "powerlessness" is more precise.

2. Power is never as specific as rights are, it always means that one can impose one's will on someone, even if this is only true in certain predefined limits, as in the case of the manager who can determine what I do during my working hours but not during the rest of the day. In the timeframe inscribed into his power, however, he can choose from a potentially infinite repertoire of tasks for me; in this sense, he really can impose his will on me, even though some tasks are excluded through employment rights. The engaged couple, on the other hand, cannot impose their will on the priest in any way; they do not even have power over the sermon he will hold on the day of the event, and therefore should take care not to irritate him too much with their demands! They can only choose between two paths that are open to them as members of the institution "church": to marry or not to marry. Rights are specific and therefore different from power; they do not allow me to freely realize my ideas, but merely protect me to a specific extent from the power of others. Rights limit the power of others.

Rights are also frequently used as a substitution for power; they replace participation in power and ease the powerlessness of the dominated. An important example of this is the modern parliamentary democracy: A common argument used against the few contemporary critics of this system (such as Johannes Agnoli) ${ }^{26}$ states that it is still "on the whole much better" than, for example, a monarchy. This advancement alone is supposed to show the strengths of democracy. In point of fact, the well-being of most citizens of a modern Western democracy is much higher than in the time of the monarchies, but this can be assigned less to an increase in the power of the citizens than to an increase in their rights. ${ }^{27}$

For average citizens, the numerous rights that they possess do in fact affect their daily lives and significantly reduce their feelings of powerlessness (especially the rights which limit the power of the judiciary, the police, the government, and the bureaucracy vis-à-vis the citizens of a state, as well as the rights to services in particular areas, such as schools, universities, welfare or public transport). On the other hand, many citizens have ceased to care about affecting government through elections and consider this a senseless undertaking, as the long-standing downward trend in voter participation shows. For an adequate treatment of topics like these, the differing properties of power and rights have to be taken into account.

4.3.4. Institutional power of position and its signs. Individual power of position, which originates inside an institution but often emanates 
into society as well, is displayed through a large range of signs: the titles of people in different institutions; the stripes of generals, decorations, and medals in the military; the letterheads and stamps of authorities, universities, and businesses.

A somewhat more complex case regards the power of position institutions have in a society. It often expresses itself in documents that are declared "official," such as identity cards, passports or the license plates of cars. Here one can speak of signs that not only mark power of position itself, but also facilitate its exercise. For example, only the police can demand of someone that they show their identity card, in Germany they even possess the right to temporarily arrest anyone who cannot produce an identity card. The card can thus be understood as an identity marker that serves to make every person reliably identifiable. This identity marker is then linked with specific data storage systems such as the "criminal record," which can be produced to examine the conduct of the respective person.

Connected to this is the system of "police registration" (polizeiliche Anmeldung), according to which in Germany every person is forced to declare a fixed place of residence. Anyone who does not declare a place of residence or declares a false one can be punished. This is a system of location control, which is supposed to enable the police to find any person they want to find. Identity markers and location controls are closely related to one another, since the latter is of little use without the first. For this reason it makes sense that in the USA, where there is no obligation to carry an identity card, there is also no location control.

Both of these legal obligations are cases of power of position that is granted to the institution "police" by the constitution or the law. Other rules regulate the power of position of the government, military, churches, etc. Businesses also have a considerable power of position in society, because they have, for example, the ability to fire people. The objection could be raised that this is not power, since it belongs to the realm of contractual freedom as in the case that I sell a product to someone, where both I and my customer are free to end the contract at any time. Such a view, however, overlooks the fact that power presents the opportunity of imposing one's will on someone due to a structural asymmetry of the situation. Such an asymmetry is present here, since the employee is dependent on his job for his salary - a dependency which becomes greater the less his chance of finding other employment - whereas the dependency is considerably less in the opposite direction. ${ }^{28}$

What all of these institutions have in common is that their power of position is expressed within the society through signs, albeit in differing forms. Churches, for example, have the right to call for their services through the ringing of bells, whereas mosques realize the same right 
through the muezzin. Today, the churches cannot impose sanctions on nonattendees, whereas in the nineteenth century is could exercise considerable power and in extreme cases could prevent people from marrying or endanger their careers.

In the case of companies, their power of position is difficult to determine, since it works differently towards different members of society. For example, companies have a high degree of power over their employees, whereas they have little power over other people; only large businesses have power over the government of a country, but this power can be significant, as shown by the concessions (subsidies, special conditions, property grants) that companies acquire for themselves using it. For the individuals of a society not employed by it, the power of position of a company mostly consists in the monopolization of discourse. Thus, for example, an individual cannot say what $\mathrm{s} / \mathrm{he}$ wants about a company; the use of a company's trademarks and logos is especially limited, so that the average member of a society is influenced by publicity without being able to reciprocate. Here, institutional power of position imparts power of interpretation. In this way, companies dominate the discourse, i.e., the discussion in the public space conducted through the media, about an increasingly important part of a culture (products, trademarks, events, as well as companies themselves and what they stand for). Advertising and publicity themselves belong to the sphere of power of interpretation.

4.3.5. Types of power of position. We have already distinguished between two components of individual power of position (4.3.2) and institutional power of position (4.3.4). A further differentiation is possible according to centrality of institutions. There is a systematic connection between individual power of position within institutions of different centrality and the power of interpretation in the society resulting from it. One can distinguish between power of position

(a) in an institution in the centre of the dominant social order (in a secular Western society this would be an institution belonging to the sphere organized by the state, such as the government, administration, parliament, police, or judiciary), which grants a high level of power of interpretation, ${ }^{29}$

(b) in an institution that is recognized by society and that therefore accords a certain level of power of interpretation (companies, churches, theatres and orchestras, successful bands or soccer clubs),

(c) in an institution that is neither recognized nor ostracized and that therefore does not possess any societal power of interpretation (little 
known institutions of all descriptions, such as most artist groups, organizations, political and interest groups etc.; private groups of people, such as a close-knit "gang" of friends),

(d) in an institution that is ostracized and therefore accords negative power of interpretation ${ }^{30}$ (for example a criminal organization, a radical political group or the demimonde).

The categories given encompass the most common cases; but since power of position is a universal phenomenon, several slightly less obvious examples might be helpful:

- A tribal elder or shaman has power of interpretation among his people because he is accorded more authority than other members of the tribe in questions of tribal politics, dispute settlements, or invocation of higher beings.

- Even in situations thought to be egalitarian, power of position often crops up, as for example in the case of roommates when only one resident signs the lease, the others becoming subtenants, ${ }^{31}$ in which case that roommate has to represent the others in negotiations with the landlord but can also threaten to kick them out of the apartment.

- Both power of position and power of interpretation were involved when, in the days before the widespread use of telephones, the owner of the only phone in a rural village (often the grocer or the parson) commanded the fastest means of contact with the outside world (power of position) and could therefore choose to share news or not (power of interpretation).

4.3.6. Power in groups and families. A complex and non-intuitive case concerns the processes of spokesmanship, disagreement, and alliance formation that permanently take place inside of any group of people. Such processes are discussed under the heading of "group dynamics" (Kurt Lewin) and are often considered to be small-scale reproductions of social power relations. In the sense of our definition, however, most of these processes are not about power; they are neither based on it nor are they "power struggles," as group dynamics would have it.

We defined power as the sum of opportunities of a person to impose his/her will due to a structural asymmetry in a given situation (cf. 2.2). For that reason, we have to distinguish between the structure of a situation and different characteristics of people. Questions of leadership in a group, however, are mostly not based on a structural asymmetry of the situation and therefore cannot be called power in our sense. That some people are more dominant than others, have more social skills or are more outspoken 
is not, in our sense, a question of power. However, in many groups there are structural asymmetries, they already start out with different roles assigned to different people. In companies or factories, people have different assignments; in a group of friends, some might have a car, etc. So in practice, power structures crop up in most groups.

In families, the major power relation exists between parents and children - a relation of nearly complete power that was only recently mitigated by giving the children certain rights. Again, relations of control between siblings, except sometimes due to age differences, cannot be said to be power, since they are mostly not rooted in a structural asymmetry of the situation and can be influenced by the children themselves.

A borderline case concerns "unwritten rules." These can lie in the domain of "group dynamics," as for example in the case of a shared apartment in which the most senior resident traditionally has the right to move into the room of someone who has just moved out. It can also, however, lie in the domain of real power relations, as when fraternities impose humiliating rituals on freshmen. The distinction can be drawn depending on whether sanctions are imposed when unwritten rules are broken. ${ }^{32}$

\section{Delimitation between the three types of power}

\subsection{Power of interpretation versus power of position}

It might initially seem as if the borderline between power of position and power of interpretation were blurred, allowing the two types of power to blend into one another. This impression can be explained by the fact that power of position almost always leads to a degree of power of interpretation (within and often outside of the respective institution). Once this is taken into account, it becomes clear that the two types of power can be clearly separated from each other.

\subsubsection{Power of position grants power of interpretation. This is true}

(a) within an institution: A member of an institution is generally awarded more attention the higher his position. In a business, a manager is more likely to determine which letterhead, which logo, or which new advertising campaign the company will use: He has power over the codes of the business. In a gang or subculture, the leaders decide what is "cool" and "uncool"; semiotically speaking, they specify which codes are accepted and used by the institution in areas such as clothing, music or slang. 
(b) outside of an institution: Here a qualification is necessary. Individuals who possess power of position in a particular institution have power of interpretation in society at large only to the extent that their institution has power of interpretation in the society (cf. 4.3.5). In this category a further distinction is required between individual power of interpretation and the power of interpretation people exercise on behalf of their institution; cf. (c) below.

Individual power of interpretation reveals itself, on the one hand, in the fact that those who possess it can express personal opinions that vary from the official position of the institution; known as "unofficial statements" which are given by a "private individual." In this case, however, it is important to remember that the person was only asked her opinion in the first place because of her power of position within the institution. Typical examples of such a situation are talk shows or interviews, where a targeted attempt is often made to elicit personal opinions differing from the official positions of the respective institution in order to get attention and generate copy. On the other hand, individual power of interpretation shows itself when individuals are asked to voice an opinion in areas that have nothing to do with their respective institutions.

(c) An institution as a whole usually has power of interpretation in a specific area: sports associations and NGOs, churches and research institutions are usually consulted only in matters relating to their area of activity; the word "consulted" is specifically used to indicate this.

When a society grants particular institutions considerable power of interpretation, the result is sometimes called Expertokratie ("expertocracy"); the term is mostly used pejoratively but has a factual basis that is valuefree, namely, that whenever an event or a problem is discussed, the opinions of individuals from such institutions to whom society grants power of interpretation in the respective field are foregrounded. In such a system, it does not harm an expert to argue superficially or to repeat clichés, sometimes it is even seen as their job to espouse a particular opinion (as in the case of lobby groups) regardless of whether there are good arguments to support it, whereas to be well-informed about a particular field doesn't help normal citizens to gain influence. ${ }^{33}$

5.1.2. Power of position without power of interpretation. Power of position usually but not necessarily entails power of interpretation. Rather, it is characterized precisely by the fact that its holders are independent in their decisions of the approval of others, and in particular of those affected. 
In Germany, the Habilitation (postdoctoral lecture qualification) has to be approved by all professors of the relevant department. Should one of them not concur, Habilitation will not be granted. This is true regardless of the reasons given, which can be completely specious. The same holds true anywhere where members of a governing body possess veto power. It doesn't matter then whether the members are generally respected or whether they have possibly long since forfeited their power of interpretation due to personal error or mediocre performance.

An example is the American Supreme Court. In this court, which is far more powerful than the highest court in Germany (the Verfassungsgericht) since it can voluntarily take up landmark cases, the judges are appointed for life by the President of the USA. Even when such a judge throws away his acceptance among the judicial community and the populace, i.e., his power of interpretation, through barely justifiable decisions, he can still exercise the same power of position as his possibly more competent colleagues.

\subsection{Power of interpretation versus power of disposition}

These two types of power are relatively easy to separate from each other, but a few comments regarding their mutual influence are in order.

The conversion of power of interpretation into power of disposition is the goal of regulations such as patent registration and trademarks. They are supposed to make it possible for individuals to obtain, through the invention of new mentifacts, control over the artifacts and texts that use them. As a rule, such rights are limited in time because legislators recognize that cultural progress would otherwise be slowed down.

Authorial rights, i.e., the idea that a text such as a book, film or song is to be regarded as "intellectual property," can be used to clarify further the border between power of interpretation and power of disposition. According to our definition, a text in and of itself belongs to the area of material culture where the concept "property" holds. Frequently, however, it also has an aspect that belongs to mental culture: When literary, filmic or other texts introduce, for example, a new type of hero (say, the "comical antihero"), ${ }^{34}$ a new narrative perspective, or a new mode of presentation, they have invented aesthetic codes, which belong to the area of secondary codes. If an author is successful in creating a new language (as George Orwell attempted in 1984, J. R. R. Tolkien in his Middle Earth novels and Anthony Burgess in A clockwork orange), he has even created a primary code. In fact, the aspect of a text which falls into the area of mental culture is usually not protected; an author who creates a new genre, intro- 
duces a new style or coins a neologism, cannot usually prevent others from using these in their texts, a notable exception being certain aspects of fiction like characters, names, and settings.

\subsection{Power of disposition versus power of position}

Power of position often involves a certain power of disposition. A typical example is the director of a museum (see 4.2.1) who, to a certain extent, has power over the works of art in "her" museum (the possessive pronoun being used for the area in which the power of position of a person holds). The example also shows that in the case of power of disposition, the differentiation according to the number of possibilities available, ranging from "special power of disposition" to "complete power of disposition," is especially important. This differentiation, however, is equally to be maintained in the case of power of position and power of interpretation; in the case of the latter it swings between the poles of someone's statement being cited, but designated "mere opinion," and the "absolute stipulation," examples for which include the "infallibility of the Pope" when speaking ex cathedra and the ukase of the Russian tsar.

For complete power of disposition, capitalist societies developed the concept of "property" (see 4.2.2). In order to facilitate the free exchange of property, money was developed as its symbolic representation. One can therefore, in these societies, reliably distinguish incomplete power of disposition attained through power of position from complete power of disposition utilizing the fact that the latter can almost always be freely converted with the help of money, while the former as a rule "cannot be bought": one can only attain it with the help of a position in an institution.

\section{Conclusion}

In this paper, three types of power were defined on the basis of cultural semiotics, further differentiated according to their properties and delimitated from each other and related concepts such as "authority." The typology of power presented here is certainly not the only one possible, but it has two important advantages: On the one hand, it builds on basic concepts of cultural semiotics, linking a social analysis of power with a clarification of its semiotic foundations; on the other hand, it can be used to analyze the full range of power phenomena and to explain many of their differences. In the introduction, we examined three examples that would normally fall under the heading of "power." Returning to them now, we recognize them as examples of the three types of power: 
1. In the case of (a) the state president or (b) the well-known personality whose utterance generates a significant media response regardless of its argumentative quality, we are dealing with power of interpretation.

2. In the case of the billionaire who builds a luxury residence, in the process claiming a piece of land for herself, using artifacts and deciding over time and skills of many people, we are dealing with power of disposition.

3. In the case of the manager who fires or hires 10,000 employees and thereby significantly influences their lives, we are dealing with power of position.

It is clear that we are truly dealing with differing power phenomena from the fact that they can be systematically differentiated by their characteristics, as demonstrated in the introduction. In Sections 4.1 through 4.3, the three main types of power and their characteristics were examined in more detail; in Sections 5.1 through 5.3 it was shown that a precise delimitation between them is possible. The suggested semiotic description of power concentrates on the sociological side of power; the aspects related to psychology and action theory are not considered. It seems to me, however, that they could be profitably examined on the basis of the theory outlined here. Most of all, I hope to have shown how closely the semiotic foundations of culture are connected to the important phenomenon of interpersonal control we are wont to call power.

\section{Notes}

* This paper is intended as a first step towards a general semiotic theory of power. I'm indebted to Roland Posner, whose elegant and clear-cut semiotic theory of culture is the basis for the work presented here.

1. In this edict of 1598 Henry IV granted French Protestants the right to practice their religion, ending the period of their persecution.

2. In this edict of 1685 Louis XIV repealed the Edict of Nantes. Many Protestants fled to other countries, where they were called "Huguenots."

3. There will be less power exercised in this case because the persons newly hired will have previously decided to apply for the job, and the subsequent changes in their living conditions will have been accounted for. The influence of the decision to hire can be the same as that of the decision to fire, in the number of affected lives as well as in the degree of the effect in each case. However, the power that is exercised is significantly less due to the cooperation of the individuals concerned.

4. In Germany, a vote out of office is impossible in the case of the president; in the case of the Federal Chancellor, it is possible when a new one is elected at the same time (a process called konstruktives Misstrauensvotum). 
5. Since this power is based on the attention of the media, it can be increased by a provocative statement, but only if this statement is not too absurd or outlandish, which could lead to decreased "quotability" of the person for the media.

6. Citations from the German text (Weber 1956 [1922], my translation).

7. In fact, this narrow concept of rule (understood here as "state power") has prevented sociologists for a long time from considering indirect power mechanisms. Implicitly, it was presupposed that "Where there's no command, there's no rule." It would be better, however, to gauge the amount of state power present in a given form of government or political system by looking at the amount of control it has over the life of the individual, be it directly (e.g., via commands and laws) or indirectly (e.g., via economic pressures or the control over private life).

8. The concept "mentifact," in the present article, is intended to be somewhat more comprehensive than the concept in Posner (2004), since it includes not only codes, but also certain conventional characteristics of their usage. The product of the use of a code is always a text (see Posner 2004: 68-70); certain characteristics of such a text, however, which cannot be inferred from the usage of the code but are not accidental either, should, in my opinion, be included in the category of mentifact. A mentifact, thus, is created when someone finds a new way to use a code and to create a text: Examples might be a new painting technique (e.g., fresco), a new concept in sculpture (e.g., "ready-made"), a new literary style ("stream of consciousness") or a new method in theatre ("epic theatre") or acting ("method-acting"). Ideas like these can in no way be inferred from the codes in the respective areas themselves, but are in fact extensions of the possibilities of using these codes; they could, however, be said to interact with the codes by proposing new ways of using them which might, later on, become conventionalised and even internalised in the codes. Therefore, to include these ideas in the concept of mentifact makes sense because they are true creations of the mind whereas, for cultural semiotics, the simple use of a code is not such a creation. These specific mentifacts, however, can be called "secondary codes" (of which "aesthetic codes" are a subset), which are based on primary codes by connecting specific ways of using them (as signifiers) with specific meanings (as signifieds).

Apart from these systematic questions, we gain the further advantage of being able to classify artistic and scientific ideas under the concept of "mentifact." In defining "power of interpretation" (see 4.1.1) we would otherwise have had to include phenomena like the construction of a new formal language (which is a code) or the definition of new concepts (which are elements of codes) in our definition, since these would be mentifacts, but to exclude others such as the development of a new mathematic formula or artistic method such as "stream of consciousness" (both not new codes, but new ways of using a code), since these wouldn't be mentifacts. This definition would be unrealistic in view of scientists and artists constantly mixing both forms of creativity whereas the simple use of a given code in a given way (let's say, in school) is usually excluded from the definition of "science" or "art." Also, it would ignore the fact that ways of using a code often are adopted by other people who form an artistic, scientific or philosophic "school," and might finally become conventionalised and be taught in normal schools like the primary codes they rest on (languages; arithmetic; mathematical logic; musical notation and harmony; etc.). These similarities are captured in the definition as "secondary codes."

9. The paper of a manuscript or the air that carries the vibrations of my voice are both also media. The former belongs to the technological media concept, the second to the physical media concept (see Posner 2004: 61). Considering the access to these media is also of course relevant to a theory of power. A comprehensive concept of media as proposed 
by Posner gives us the potential to describe power relations as they occur in the interaction between disabled and non-disabled individuals, between locals and foreigners, or between illiterate and literate people (the last two examples with the aid of the coderelated concept of media, which sees local languages or scripts as mediums).

10. At the same time they are considered by many societies to be "objectively real and true." While the conventionality of values in a society was comparatively easy to understand, the same recognition took an especially long time with regard to concepts.

11. There it might be impossible for a girl to reject the husband chosen for her on the grounds of his "saying stupid things" (lack of natural authority), but possible on the grounds of his "being below her station" (lack of status).

12. Naomi Klein discusses these problems and positions, among others, in her book No logo (Klein 2000). Though it is often thought to be the "manifesto of the antiglobalization movement," the book is primarily a journalistic portrayal of the first years of the movement, together with some in-depth analysis of the reasons it came into being and its foremost topics and strategies. It also gives an account of the trend to "branding," which became pervasive in the 1990s. Concerning the problem of branding and artistic freedom, Klein describes how artists in the USA, working in a postmodern culture of eclecticism and citation, do not have the same opportunities to realize their artistic vision; thus, artists who sign with multinational companies are able to experiment freely and let the lawyers clear each and every sample they use, whereas freelance artists doing the same thing have to work "illegally" and might face severe consequences.

13. The Canadian quarterly "Adbusters" publishes "enhanced" versions of well-known advertisements, reports new fakes and "embellishments" of billboards. Semiotically speaking, the critique of Adbusters aims at the one-way flow of information in advertising and publicity; they postulate a loss of public space and a deterioration of the "mental environment," which could be translated to "mental culture." All the activities described above, as well as "flash mobs," "Google bombing," and politically motivated fakes (e.g. forged parking tickets for SUVs), are examples of "Culture Jamming," which could be described as subversive, disconcerting, and often illegal attempts to reclaim "mental culture" from those imbued with power of interpretation, done by and for people who, without Culture Jamming, would have no power of interpretation.

14. For the same reason, its generality, Radeberger failed to get it protected as a trademark (Bundespatentgericht, Beschluss vom 14.05.1997, 26 W (PAT) 7/97, GRUR 1998, 57).

15. For a discussion of the centrality of codes to a society see Posner (2004: 78-81).

16. At the same time, there were individual texts that were crucial to the formation of this mentifact, such as the anonymous "Historia von D. Johann Fausten, dem weitbeschreyten Zauberer vnnd Schwartzkünstler" of 1587" (the so-called "Faustbook" that became Goethe's main source).

17. I use the concept "complete power of disposition" for a kind of power in which every possibility of disposition is included. The term "absolute power," which is typically used for absolute monarchies, wasn't adapted, since it is semantically linked to a type of rule. This type of rule is not necessarily combined with complete power of the ruler. An absolute monarch, under certain circumstances, might be lacking some possibilities, because they might provoke a coup of the military; in this case he doesn't have complete power. Because of its connection with a type of rule, absolute power, if used for power of disposition (the power over artefacts), sounds rather metaphorical.

18. In German the equation of power of disposition with achievement or quality is reflected in a number of expressions such as verdienen ("to earn" and "to merit") or Verdienst ("earnings" and "merit") for receiving power of disposition or wertvoll ("valuable" and 
"estimable") for something that can be exchanged for a significant amount of power of disposition.

19. For the concepts "culturally central" (zentralkulturell), peripher kulturell (culturally peripheral), and gegenkulturell (counter-cultural), see Posner (2004: 75).

20. This example can be used to demonstrate the connection between power of disposition and power of interpretation. Wherever the distribution of one type of power shows a close correlation to the other, there will be little chance of reducing the importance of power of disposition in a society. In the case of 1950s America and the McCarthy era, the privatization of the relatively new media radio and television (cf. McChesney 1993) played an important role in the general circulation of the "red scare."

21. "Das Wesen der Organisation liegt [f ür Heller] in einem zirkulären Bedingungszusammenhang, bei dem die Macht der Organe die Macht der Mitglieder und die Macht der Mitglieder wiederum die Macht der Organe bewirkt, wobei das Ergebnis eine Steigerung der Organisationsmacht, also der Macht des Ganzen, ist" (Berthold 1997: 357).

22. Thompson goes on to give the following definition of power: "In the most general sense, power is the ability to act in pursuit of one's aims and interests, the ability to intervene in the course of events and to affect their outcome" (1995: 13).

23. At least, none of them seems to have tried.

24. A major difference between "established churches" and those called sects can be seen in the fact that only the leaders of the latter (sometimes called "gurus") have the power to dissolve the institution. This may be an important part of the meaning of the word "established."

25. Notable exceptions are extremely hierarchic organizations, e.g., totalitarian states; there, the degree of subordination is nearly the same on every level.

26. Agnoli diagnoses an "involution" of modern democracy, a kind of degenerative process which causes a regression from liberal and progressive beginnings to a consolidation of new power structures only superficially covered by democratic elements, finally thwarting the ideals with which democracy began (cf. Agnoli 1990).

27. The factual powerlessness of the people became obvious when England, Italy and Spain participated in the Iraq war in 2003. In all three countries seventy or eighty percent of the population in polls had voiced their opposition to the participation. The decision to go to war, however, might well be the most important decision a state can make; when it is decided in clear opposition to the people, the application of the word "democracy" becomes inconsistent.

28. In special cases, the dependency of an employer on an employee may be greater than the other way around, for example if the employee is a much sought after specialist in a certain area whom the employer could hardly replace.

29. It might be objected that the membership in such an institution may, under certain circumstances, accord less recognition than in the private or cultural sector; for example, famous artists or leading intellectuals often are more popular than politicians or judges. This fact, however, is readily explained with the important differentiation between power of interpretation and natural authority (cf. 3.1). Important politicians have great power of interpretation because the media reports their views independently of the quality their arguments and thinking show. Intellectuals or artists, on the other hand, will only be visible in the media when they have already gained a reputation in a certain area; they have natural authority in that area. But natural authority plays a role in politics, too, when for example a parliamentarian is asked because $s /$ he is known to be an expert for the topic in question. More important, however, is power of interpretation, which can be seen by the fact that a chancellor, president or chairman will be asked 
more frequently for their opinion than a normal parliamentarian, independently of their respective areas of expertise.

30. Negative power of interpretation can be said to exist when a sign user is discouraged and/or deterred from distributing mentifacts as a part of his culture's mentality. Negative power of interpretation is present in society, for example, when someone is only quoted by the media with insinuations not to take him seriously, in negative contexts, or followed by opposing statements. Negative power of interpretation also exists inside of institutions, as when theatre critics are suspicious of an actress because she played in soap operas before, which actually makes it harder for her to succeed.

31. In German Wohngemeinschaften (flat-sharing communities) this is often practiced for technical reasons.

32. I understand a "sanction" to be outside the socially accepted range of negative reactions in human interaction, examples for the latter being hostility, sulking, brushing off and also (at least until a certain age is reached) brawls and fights. Understood in this sense, "to shower someone with urine" would be a sanction, whereas "to ignore him/her for weeks" wouldn't be, although it may be intended as a punishment, too. People will always show a negative reaction if they feel disregarded, but usually they will do this in the limits of what is culturally accepted as "normal behavior" depending on age, sex, and social standing. As a rule, they will overstep these limits only when safeguarded by power relations. In the absence of power, every measure I take against someone might be reciprocated, so I have good reason to avoid escalation.

33. Since the informational capacity of the media has multiplied in the last years, nonspecialists are increasingly often asked their opinion. Thus, power of position is no longer a necessary condition for an opportunity once in a while to distribute your mentifacts, be these ideas, plans, theories, opinions or otherwise. However, it is still crucial for the value attached to the respective mentifacts: A brilliant theory or argument voiced by a "nobody" in a talk show will probably be cited less frequently than a superficial statement from a person with power of position (a top manager, director or anchorman).

34. Such an introduction can be attributed to Cervantes' Don Quixote.

\section{References}

Agnoli, Johannes. 1990. Die Transformation der Demokratie und andere Schriften zur Kritik der Politik. Freiburg: ça ira.

Berthold, Lutz. 1997. Transitive Macht, intransitive Macht und ihre Verbindung: Hermann Hellers Begriff der Organisation. In Gerhard Göhler (ed.), Institution - Macht — repräsentation: Wofür politische Institutionen stehen und wie sie wirken, 349-359. Baden-Baden: Nomos.

Heller, Hermann. 1934. Staatslehre. Leiden: Sijthoff.

Henderson, Allen H. 1981. Social power: Social psychological models and theories. New York: Praeger.

Klein, Naomi. 2000. No logo: Taking aim at the brand bullies. Toronto: Vintage Canada.

McChesney, Robert W. 1993. Telecommunications, mass media, and democracy: The battle for the control of US broadcasting, 1928-1935. New York: Oxford University Press.

Posner, Roland. 2004. Basic tasks of cultural semiotics. In Gloria Withalm \& Josef Wallmannsberger (eds.), Signs of power, power of signs: Essays in honor of Jeff Bernard, 5689. Wien: Inst. 
Thompson, John. 1995. The media and modernity: A social theory of the media. Cambridge: Polity Press.

Weber, Max. 1956 [1922]. Wirtschaft und Gesellschaft, 2 vols. Tübingen: Mohr.

Martin Siefkes (b. 1977) is a PhD candidate at Technical University Berlin < Martin_Siefkes@ gmx.de>. His research interests include theoretical semiotics, communication theory, cultural semiotics, and literary deconstruction. His recent publications include "Unkooperativität und andere kommunikative Randphänomene in 'Die Zeit und das Zimmer' von Botho Strauß" (2008); Zeichenmaterialität und Zeichenträger bei stilistischen Zeichen (2009); "Die Landschaft der Zeichen: W. G. Sebalds 'Die Ringe des Saturn"” (2009); and "Der blonde Zopf und die Gewalt der Sprache: Eine dekonstruktivistische Lektüre des Märe 'Der Pfaffe mit der Schnur (C)'", (2008). 
Bereitgestellt von | Technische Universität Berlin Angemeldet Heruntergeladen am | 27.11.17 16:30 